\title{
Access of Marginalized Groups for Free Surgical Camp in Remote Areas of The Midwestern Regionof
}

\section{Nepal}

Suresh Rasaily MD ${ }^{1, ~ *, ~ K a u s h a l ~ P o k h r e l ~ M D ², ~ S a n t o s h ~ S u b e d i ~ M D ², ~ S u l a x m i ~ K a t u w a l ~ M D ~}{ }^{1}$, Salikram Gautam¹,Om

\section{Prakash Yadav ${ }^{1}$}

${ }^{1}$ Rapti Eye Hospital, Dang, Nepal

${ }^{2}$ Chhanda Kale Babu Narayani Eye Hospital, Kapilvastu, Nepal

*Corresponding Author: Suresh Rasaily, Rapti Eye Hospital, Dang, Nepal

Received date: 23 January 2021; Accepted date: 18 February 2021; Published date: 25 February 2021

Citation: Rasaily S, Pokhrel K, Subedi S, Katuwal S, Gautam S. Access of Marginalized Groups for Free Surgical Camp in Remote Areas of The Midwestern Region of Nepal. J Comm Med and Pub Health Rep 2(2): https://doi.org/10.38207/jcmphr20210005

Copyright: () 2021 Suresh Rasaily. This is an open-access article distributed under the terms of the Creative Commons Attribution License,which permits unrestricted use, distribution, and reproduction in any medium, provided the original author and source are credited.

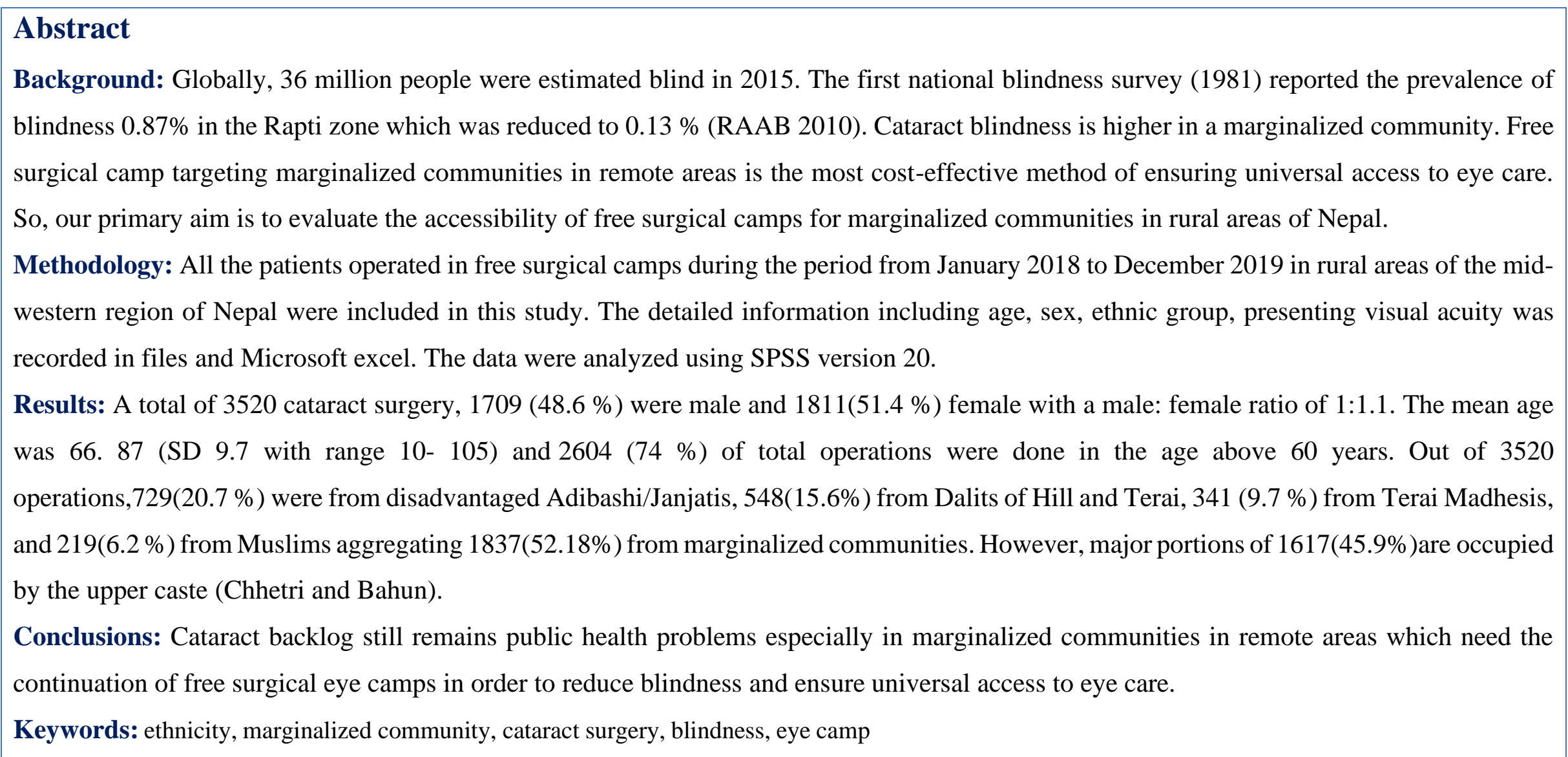

\section{Introduction}

Globally, 36.0 million people were estimated to be blind in 2015 , whereas 216.6 million people had moderate or severe vision impairment [1]. Ninety percent of the blind and visually impaired hailed the developing world, with particular concentrations seen in South Asia and sub-Saharan Africa (SSA). The elderly people (> 50 years) are usually affected necessitating children and/or grandchildren to stay with them to worry for the blind thereby compelling children for school dropout and adult out of work [2] National Blindness Survey (1980-1981) conducted in Nepal, estimated the prevalence of blindness to be $0.84 \%$ (best-corrected VA $<3 / 60$ within the better eye), with cataract being the leading explanation for blindness accounting for $66.8 \%$ of the entire blindness [3]. Itis also reported that the blindness prevalence of 0.87 $\%$ in the Rapti zone, which was reduced to $0.13 \%$ in Rapid Assessment of Avoidable Blindness 2010 [3]. As per the 2011 census, Nepal has 126 caste and ethnic groups among which Chhetri is the However, their participation is essentially suffering from person- largest having $16.6 \%$ of the total population followed by BrahmanHill (12.2\%), Magar (7.1\%), Tharu (6.6\%), Tamang (5.8\%), Newar (5\%), Kami (4.8\%), Musalman (4.4\%), Yadav (4\%) and Rai (2.3 $\%) 4$. The Nepal Foundation for Development of Indigenous Nationalities (NFDIN) Act-2002 defined and further classified 59 Adivasi/Janajati into five groups comprising endangered, highly marginalized, marginalized disadvantaged, and advanced group [4]. National Dalit Commission of Nepal has defined and listed 26 castes as Dalits from the hill and Terai region [5]. Social exclusion and discrimination against Dalits, disadvantaged Janajati, Muslims, and Madhesis is the root cause for the poor social development of Nepal. The constitution of Nepal has defined and listed Indigenous peoples, women, Madhesis, Dalits, and other religious minorities as poor and marginalized communities in Nepal [6]. Making services available by organizing free health camps is one of the effective methods to deliver health services for those disadvantaged marginalized communities.

related and /or service-related barriers that must be addressed. Rapti 
Eye Hospital(REH) running under Nepal Netra Jyoti Sangha (NNJS) has developed an innovative team approach for free of charge surgical camp providing low-cost, high-quality care by maximizing each member's performance and mobilizing local volunteers in remote areas. This approach has empowered a surgical team of 1ophthalmologist and cadres of an ophthalmic assistant with local

\section{Methodology}

This prospective cross-sectional study was approved by the hospital management board and was performed in accordance with the tenets of the Declaration of Helsinki. All the patients who underwent cataract surgery in free surgical camps during the study period from January 2018 to December 2019 were included. The detailed information including age, sex, ethnic group, presenting visual acuity of each eye, place, type of surgery, IOL power, uncorrected visual acuity of first post-operative day, and complications if any were recorded. Each patient was categorized into ethnic/ caste groups as per the health management information system of Nepal and marked as belonging to a marginalized community or not. However, Indian

\section{Organization of free surgical camp:}

The free surgical camp was organized either felt would like from base hospital or on demand of rural governmental or non-governmental organizations (NGO) in health care centres or school building.

\section{Role of a base hospital:}

Base hospital was responsible for detailed planning, implementation

\section{Role of the surgical team:}

The highly motivated surgical team comprising one ophthalmologist, ophthalmic paramedics, laboratory technician, and maintenance persons provided medical treatment and surgery for operable cataract cases free of cost. The operable cataract cases underwent blood pressure record, syringing test, intraocular pressure measurementwith Schutz's tonometer, a blood test for random blood sugar (RBS), and serological test for HIV, HBsAg, and HCV. After taking informed consent for regional anaesthesia and surgery, digital biometry was done to calculate the required power of intraocular lens and pupil dilated with tropicamide1 \% plus phenylephrine $5 \% \mathrm{w} / \mathrm{v}$. Under

\section{Results}

During two years, 2018-2019, 34 free surgical camps were organized in remote areas where $1825(51.8 \%$ ) right eyes and 1695(48.2\%) left eyes, altogether of thirty-five hundred and twenty (3520) were operated. Out of a total,1709 (48.6\%) were performed in males and 1811(51.4\%) were in females with a male: female ratio of $1: 1.1$. The mean age of presentation was 66.87 (SD 9.7 with range 10- 105). Maximum operations1530(43.5\%) were performed in the 61-70 years age group, followed by $883(25.1 \%)$ and $690(19.6 \%)$ in the 71-80 and 51-60 age group, respectively. Congenital volunteers to perform over a hundred cataract surgeries during a day. However, the availability of free surgical services for underprivileged marginalized groups is often questionable and sometimes not evaluated to date. So, our primary aim is to work out the accessibility of marginalized groups for a free of charge cataract surgery camp organized by Rapti Eye Hospital in provinces 5 and 6 .

patients who participated in the free surgical camp in Kapilvastu district were kept in the foreign category. The data were entered in Microsoft Excel 2016 (Microsoft Corporation, Redmond, Washington, USA) and statistically analyzed using StatisticalPackage for Social Sciences version 20 (SPSS, Inc. Chicago, IL, USA). For descriptive statistics, percentage, mean, standard deviation was calculated along with the graphical and tabular presentation. One-way analysis of variance was used to compare continuous variables and Chi-square test for comparing categorical variables across different ethnic groups. The test of significance was consideredsignificant when the $\mathrm{p}$-value was $<0.05$.

of outreach activities in a feasible way.

\section{Role of the local organizer:}

The local organizer helps in the identification of the site, wide publicity, the arrangement of infrastructure and provides for hasslefree during camp and maintain systematically patient's flow.

aseptic precaution, Manual Small Incision Cataract Surgery (MSICS) with single piece polymethylmethacrylate intraocular lens (PMMA IOL) in the capsular bag was done under the peribulbar blockwith xylocaine $2 \%$ with adrenaline 1: 200000 IU plus hyaluronic acid1500 IU. Any complications if occurred noted an eye-patched with the gauze pad. The operated eye was examined with the portable slit lamp, uncorrected visual acuity (UCVA) was recorded, and patients were discharged on topical antibiotics and steroids after thorough counselling. The patient was advised to follow up nearby eye care centre after 1 week.

and traumatic cataracts below 40 years comprised only $46(1.3 \%)$ cases. The presenting study reported $1136(32.3 \%)$ of total operated patients were pseudophakic in the fellow eye followed by $2122(60.3 \%)$ immature senile cataract and $273(6.7 \%)$ mature cataracts in both eyes. One thousand five hundred ninety-six $(45.3 \%)$ eyes had visual acuity $<3 / 60$ whereas $1188(33.8 \%$ ) eyes had visual acuity 6/24-6/60. The presenting visual acuity of operated eyes was categorized as shown in (Table 1). 
Table 1: pre-operative visual acuity of operated eye

\begin{tabular}{|l|l|l|l|}
\hline Ethnic group & Male & Female & Total \\
\hline Dalits hill and terai & 253 & 295 & 548 \\
\hline Disadvantaged adibashi/janjatis & 349 & 380 & 729 \\
\hline Non-Dalit terai Madhesis & 171 & 170 & 341 \\
\hline Muslims & 110 & 109 & 219 \\
\hline Relatively advantaged adibashi/janjatis & 9 & 12 & 21 \\
\hline Upper caste & & & \\
\hline Foreigners & 802 & 815 & 1617 \\
\hline Total & 15 & 30 & 45 \\
\hline
\end{tabular}

Marginalized communities were maximally benefited from these free camps. In total,1837 (52.18\%) operations done were from politically economically and socially backward communities. Of these, 729(20.7\%) operations done were from disadvantaged Adibashi/Janjatis, 548(15.6\%) from Dalits of Hill and Terai, 341 (9.7 \%) from Terai Madhesis, and 219(6.2 $\%)$ from Muslims. However, 1617(45.9\%) patients belong to the upper caste and forty-five $(1.3 \%)$ were Indian. The ethnic/caste-wise distribution of free cataract surgery in a camp setting is as shown in (Table 2).

Table 2: Number of operations done in different ethnic/caste groups

\begin{tabular}{|l|l|l|}
\hline Visual acuity & Number & \% \\
\hline $\mathbf{6 / 6 - 6 / 1 8}$ & 68 & 1.9 \\
\hline $\mathbf{6 / 2 4 - 6 / 6 0}$ & 1188 & 33.8 \\
\hline $\mathbf{5 / 6 0 - 3 / 6 0}$ & 668 & 19 \\
\hline $\mathbf{2 / 6 0 - 1 / 6 0}$ & 773 & 22 \\
\hline CF- PLPR & 823 & 23.4 \\
\hline Total & 3520 & 100 \\
\hline
\end{tabular}

People from 14 districts were benefited from the free surgical camps. Out of 3520 operations, 950(26.9\%) were from the Salyan district followed by $923(26.2 \%)$ Kapilvastu, 562(15.9\%) Bardiya and,427(12.1\%) Rukum west. However, forty-three (1.2\%) Indian patients from the border area were also operated in these camps. The geographical distribution of patients who underwent cataract surgery is shown in the bar diagram (Figure 1).

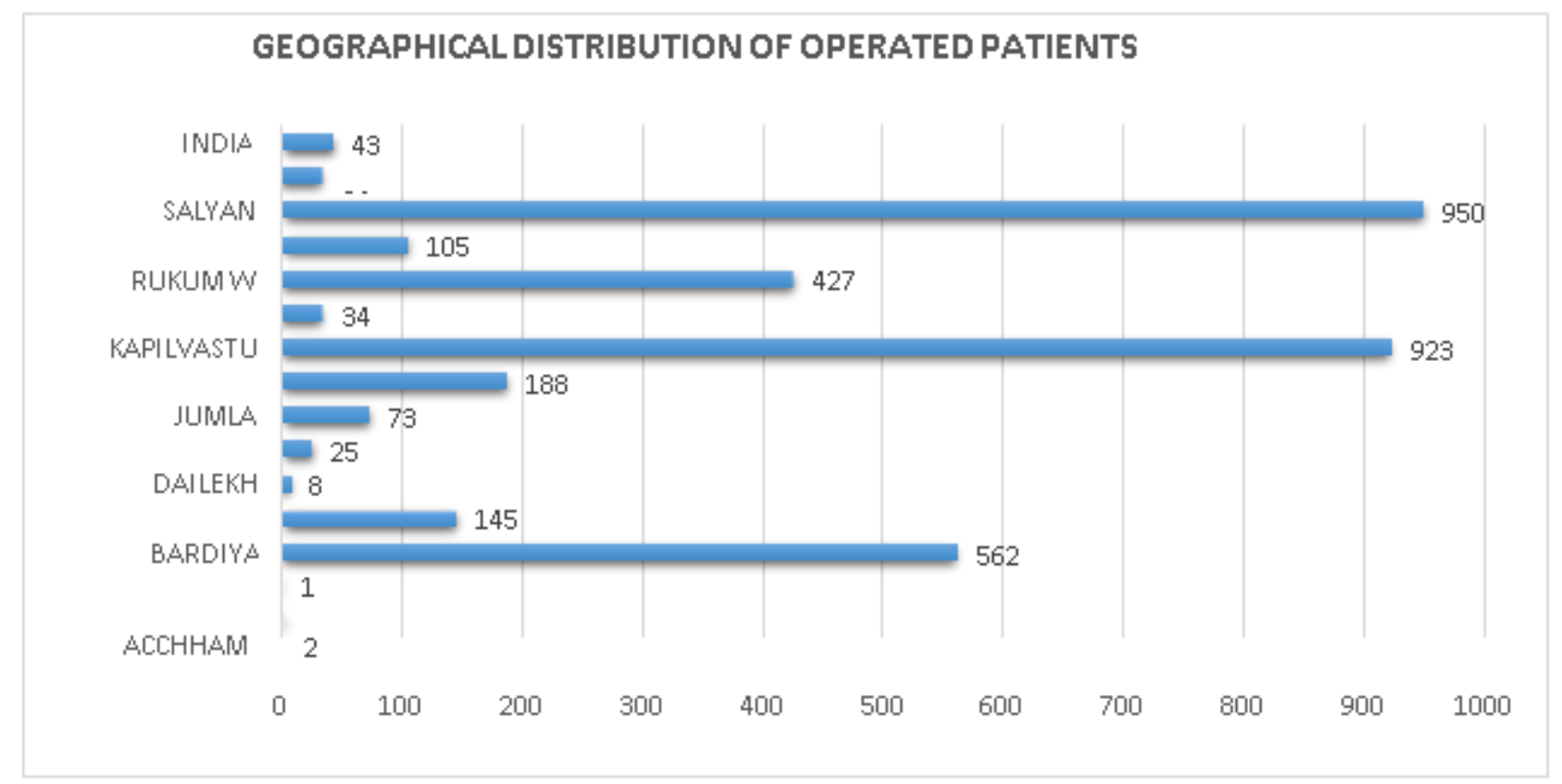

Figure 1: Geographical distribution of operated patients

The uncorrected visual acuity on $1^{\text {st }}$ postoperative day was good ( $\geq$ $6 / 18)$ in $3014(85.6 \%)$ operated cases followed by borderline $(6 / 24-$ $6 / 60)$ in $401(11.4 \%)$ and poor $(<6 / 60)$ in $105(3 \%)$. The most common intraoperative complication was a premature entry in $42(1.2$ $\%$ ) followed by posterior capsule rupture in $21(0.6 \%)$. The frequent complications during the immediate postoperative period were striate 
keratopathy in 250(7.1\%), corneal edema in 145(4.1\%), and hyphema in 54(1. 5\%). The frequent intraocular and postoperative complications on day 1 are shown in (Table 3). The mean IOL power used was 21.45(SD 1.94 range 6-28.5). The mean IOL power differences among ethnic/caste groups were not statistically significant (p-value 0.75).

Table 3: Frequent intraoperative and post-operative complications on day 1

\begin{tabular}{|l|l|l|l|}
\hline $\begin{array}{l}\text { Intraoperative } \\
\text { complications }\end{array}$ & Number(\%) & $\begin{array}{l}\text { Post-operative } \\
\text { complications on Day1 }\end{array}$ & Number(\%) \\
\hline Premature entry & $42(1.2 \%)$ & Hyphema & $54(1.5 \%)$ \\
\hline PCR with IOL in sulcus & $2(0.06 \%)$ & Wound leak & $40(1.1)$ \\
\hline PCR with ACIOL & $19(0.5 \%)$ & Epithelial defect & $16(0.4)$ \\
\hline PCR without IOL & $3(0.1 \%)$ & Striate keratopathy & $250(7.1 \%)$ \\
\hline Iridodialysis & $3(0.1 \%)$ & Corneal edema & $145(4.1 \%)$ \\
\hline DM stripping & $16(0.4 \%)$ & Peaking pupil & $22(0.6 \%)$ \\
\hline Total & $85(2.4 \%)$ & Total & $527(14.9 \%)$ \\
\hline
\end{tabular}

\section{Discussion}

A cataract is a leading cause of avoidable blindness in developing countries that need a surgical extraction. However, poor accessibility and poverty are major barriers to cataract surgical coverage in remote areas of Nepal. Organizing free eye surgical camps in remote areas is one of the cost-effective methods to reduce avoidable blindness by performing manual small incision cataract surgery. Manual small incision cataract surgery is the procedure of choice in developing countries as it provides similar outcomes as compared to phacoemulsification with low cost and less time consuming [7] According to the latest WHO data published in 2018 total life expectancy of Nepalese is 70.2 years. The presenting study showed most of the operated patients $1530(43.5 \%)$ were in the the61-70 years' age group followed by $883(25.1 \%)$ and $690(19.6 \%)$ in the 71-80years and 51-60 age group, respectively. Only 192(5.5\%) operations were done in the age above 80 years. We came to know that $74 \%$ of total operations were done in the age above 60 years. Delayed age of presentation with advanced stage cataract in free surgical camp is mostly due to lack of escort to the base hospital, economical dependency on careless offspring and inaccessibility to health facility get operated at the optimum time. However, a study was done by Sharma and Joshi [8] in India showed that the majority (75\%) of patients receive delayed eye care and come in advanced stages of cataract. The mean age of operated patients in our study was $66.87 \pm 9.7$ with age ranged from10 -105 years which is similar to $65.8 \pm 9.4$ with the age ranged from 40 to 99 years in a study done in the far western region of Nepal [9]. The youngest patient of 10 years had a congenital cataract. The presenting study showed $48.6 \%$ male and $51.4 \%$ female with a male: female ratio of $1: 1.1$ was operated in camps which indicates proportionate utilization of free surgery by women. However, Sitaula et al. (2016) [10] reported males (57 \%) predominance over females $(43 \%)$ for the utilization of free surgery in camps which contradicts our findings.

In the present study, 1596(45.4\%) of total operated eyes had preoperative visual acuity < 3/60, $668(19 \%)$ eyes had visual acuity < $6 / 60-3 / 60$, and $1188(33.8 \%)$ eyes had pre-operative visual acuity $<6 / 18-6 / 60$. However, Manandhar et al (2018) [11] reported preoperative visual acuity $<3 / 60$ in $47.2 \%$ of eyes, visual acuity $<6 / 60$ $3 / 60$ in $16.7 \%$ of eyes, and $<6 / 18-6 / 60$ in $36 \%$ of eyes which are similar to our findings. We found $68(1.9 \%)$ operated eyes had preoperative visual acuity up to $6 / 18$ which is higher than $0.4 \%$ reported in an Indian study by Sharma and Joshi (2020) [8]. About 31(0.9\%) one-eyed patients having no vision in other eyes were operated which is lesser than 199 (7.9 \%) one-eyed cases reported in Sharma and Joshi (2020) [8]. One-eyed patients were most challenging for surgeons because they require highly skilled competent surgeons as there is no margin of error. However, all the one-eyed patientsrestored good visual outcomes on 1st post-operative day. National census 2011 reported Chhetri and Bahun's larger ethnic groups in Nepal occupying $16.6 \%$ and $12.2 \%$ of the total population (CBS- 2011) [12]. The present study showed $45.9 \%$ of total operations wereperformed in people of the so-called upper caste (Bahun and Chhetri) whereas marginalized communities share $52.2 \%$ of total operations.Among marginalized communities, disadvantaged adibashi/janjatis occupied $20.7 \%$ followed by $15.6 \%, 9.6 \%$, and $6.2 \%$ by Dalits, Madhesis, and Muslims, respectively. However, females constituted $51.9 \%$ of operations among marginalized communities. This indicates no gender disparity in utilizing free surgical services in camps. To our knowledge, none of the studies has been published in Nepal reporting caste /ethnic distributions of free cataract surgery utilization so far. However, an epidemiological study [8] of patients availing free cataract surgery in India showed $56.84 \%$ female vs $43.16 \%$ male patients from backward caste were operated on. In ourstudy, $26.9 \%$ 
of total operations were done in people from the Salyan district followed by $26.2 \%$ Kapilvastu, $15.9 \%$ Bardiya, $12.1 \%$, Rukum West, $5.3 \%$ Kalikot, and $3.1 \%$ Rukum East. This indicates that our outreach activities are focused on remote areas where there are no surgical centers, and the cataract backlog is high. So, we triedour best to cover people from 14 districts in provinces 5 and 6.

However, forty-three $(1.2 \%)$ patients from the neighboring countries especially India were also operated on at Kapilvastu. This is probably due to the open border where free movement of people of either country is allowed and our primary aim to remove cataract and restoration of sight whoever participates in the camp. In our study, uncorrected visual acuity was recorded on day one after the operation and the visual outcome was categorized as per World Health Organization (WHO) protocol. By WHO definition, a good outcome is $\mathrm{VA} \geq 6 / 18$, borderline VA 6/24-6/60, and a poor outcome is VA< $6 / 60$. We found good visual outcomes in $85.6 \%$, borderline outcome in $11.4 \%$, and poor outcome in $3 \%$ of total operations which are comparable with visual outcomes described by Manandhar et al. (2018) [11]. However, the immediate post-operative visual outcome was more than recommended by WHO $(80 \%)$. The borderline and poor visual outcomes are probably due to striate keratopathy and corneal edema. We recorded uncorrected visual acuity on the 1st POD for all the operated patients because it is very difficult for poor people to get refraction and spectacles after cataract surgery in remote areas. Thus, uncorrected visual acuity after surgery is particularly important for this type of publication [7,13,14,15]. A total of 85(2.1\%) operated eyes had intraoperative complications in our study with premature entry being the most common $42(1.2 \%)$ followed by posterior

\section{Conclusion}

Cataract backlog remains public health problem especially in rural areas of Nepal. Good visual outcomes can be achieved even in a camp setting with the appropriate surgical techniques. However, marginalized communities who are socially, economically, and politically disadvantaged will continue to need free surgical camps in rural areas on regular basis to ensure universal access.

\section{References}

1. Bourne RR, Flaxman SR, Braithwaite T, Ackland P, Braithwaite Tet al. Global causes of blindness and distance vision impairment 1990-2020: a systematic review and meta-analysis. Lancet Glob Health. 5(12): 1221-1234.

2. Nikpoor N, Hansen ED, Oliva, MS, Geoffrey T, Sanduk R (2018) Elimination of preventable blindness: can success in Nepal bereplicated in Africa? Innovation and Entrepreneurship in Health. 5(1): 27-39.

3. Brilliant LB, Pokhrel RP, Grasset NC, Lepkowski JM, Kolstad A, et al. (1985) Epidemiology of blindness in Nepal. Bull World Health Organ. 63(2): 375-386.

4. NEFIN (2004): 'Classified Schedule of Indigenous Nationalities of capsule rupture in $24(0.68 \%)$. All posterior capsule rupture cases underwent manual anterior vitrectomy, and the anterior chamber intraocular lens was implanted in $19(0.5 \%)$ and IOL in sulcus in $2(0.06 \%)$ whereas $3(0.1 \%)$ eyes were kept aphakic. However, Manandhar et al. (2018) [11] reported that $6 \%$ of total patients had intraoperative complications with a premature entry in $2.1 \%$ which is higher than that of our study. The posterior capsule rupture (0.68 $\%$ ) in our study was fewer than that reported in several studies done in Nepal and India $1.9 \%, 3.63 \%$, and $20.5 \%$ [13,15,16]. The frequent complications during the immediate postoperative period were striate keratopathy in 250(7.1\%), corneal edema in 145(4.1\%), and hyphema in 54(1.5\%). Ninety-six patients underwent manipulation on the first post-operative day on the campsite. Among them, 40 eyes had sclera-corneal suturing for wound leak, 50 eyes had hyphema wash and 16 eyes had pad and bandage for the corneal epithelial defect. In our study, $14.9 \%$ of operated eyes had postoperative complications on day 1 with striate keratopathy $(7.1 \%)$ being most common. Other complications like corneal edema $(4.1 \%)$, epithelial defect $(0.4 \%)$, and hyphema $(1.5 \%)$ were responsible for the borderline visual outcome on day 1 . Our post-operative complication rate was comparable to $15 \%$ reported in Manandhar et al. (2018) [11] but higher than the other three studies 9.3\%, $9.3 \%$, and $6.2 \%$ respectively $[\mathbf{1 3 , 1 7 , 1 8}]$. However, a study done in Pakistan reported hyphema (4.2\%) being the most common complication [19]. Higher complications that we reported were probably due to inappropriate use of viscoelastic substances, the learning curve of the surgeon, and inadequate illumination of a portable operating microscope.

\section{Conflicts of interest: Nil}

Financial conflict: Nil

\section{Acknowledgment}

Nepal Netra Jyoti Sangh, Norwegian Agency for Blind and Partially sighted DAK Foundation, Local Government, Dr. Nita, Dr. Jyoti, Dr. Aric, Mr. Samsher Thapa, Mr. Kiran Poudel, and Mr. Jasraj BK.

Nepal', prepared by the Janajati Classification Task Force andapproved by the Federal Council of NEFIN.

5. Nepal Government, National Dalit Commission Act, 2074 (2017).

6. The constitution of Nepal (2015). Article No.306.Definition and interpretation.

7. Ruit S, Tabin G, Chang D, Bajracharya L, Kline DC, et al. (2007) A Prospective Randomized Clinical Trial of Phacoemulsification Vs Manual Sutureless Small-Incision Extracapsular CataractSurgery in Nepal. Am J Ophthalmo. 143(1): 32-38.

8. Sharma VK, Joshi MV (2015) Epidemiological study of patients availing free cataract services of a national program of control of blindness. J Clin Ophthalmol Res 3(1): 9-13. 
9. Bhatta RC, Krishnaiah S, Pant BP, Sapkota YD (2011) Outcome ofthe Manual Small Incision Cataract Surgery at the Base Hospital and Improved Surgical Eye Camps in Nepal: A Prospective Observational Comparative Study. J Clinic Experiment Ophthalmol2(9): 186.

10. Sitaula et al. (2016) Journal of Chitwan Medical College 6(16).

11. Manandhar et al. (2018) Cataract surgery in hilly areas. Asian Journal of Medical Sciences 9(4).

12. Government of Nepal, Central Bureau of Statistics (CBS). Nepal Living Standards Survey Household 2010-2011, Statistical Report.

13. Venkatesh R, Muralikrishnan R, Balent CL, Prakash SK, Venkatesh NP (2005) Outcomes of high-volume cataract surgeries in a developing country. Br J Ophthalmol 89(1): 1079-1083.

14. Kapoor H, Chatterjee A, Daniel R, Foster A (1999) Evaluation of visual outcome of cataract surgery in an Indian eye camp. Br J Ophthalmol 83(1): 343-346.

15. Hennig A, Kumar J, Yorston D and Foster A (2003) Sutureless cataract surgery with nucleus extraction: Outcome of a prospective study in Nepal. Br J Ophthalmol 87(1): 266-270.

16. Zaman M, Shah AA, Hussain M, Baba TF, Khan MT, et al. (2009) Outcome of sutureless manual extracapsular cataract extraction. J Ayub Med Coll Abbottabad 21(1): 39-42.

17. Hosamani S, Vallabha K and Warad V (2015) Post-operative complications and visual outcome in eye camp patients undergoing sutureless cataract surgery at a Base Hospital in Vijayapura District, South India. Niger J Ophthalmol 23(1): 16-21.

18. Limbu B, Jha HC (2014) Intraoperative Complications of High Volume Sutureless Cataract Surgery in Nepal: A Prospective Study.Kathmandu Univ Med J 47(3): 194-197.

19. Khan MT, Jan S, Hussain Z, Karim S, Khalid MK et al. (2010) Visual Outcome and Complications of Manual Sutureless Small Incision Cataract Surgery. Pak J Ophthalmol 26(1): 32- 38. 